\title{
Customer lifetime value determination and strategic implications for a cruise-ship company
}

Received: 26th June, 2003

\section{Paul D. Berger}

is a professor of marketing at the School of Management, Boston University. He is co-author of a number of books and has published a variety of journal articles. He has extensive consulting experience in the areas of direct marketing, marketing research and experimental design.

\section{Bruce Weinberg}

serves as an associate professor of marketing and e-commerce at Bentley College's McCallum Graduate School of Business. His expertise is in online consumer behaviour, particularly online shopping and customer service, internet auctions and online banking and bill payment. He has received awards for both teaching and research and his publications have appeared in a range of marketing journals.

\section{Richard C. Hanna}

is an assistant professor of marketing at the Carroll School of Management at Boston College. His research interests include database marketing, internet marketing, marketing research techniques, pricing strategy and promotions. He is an active member of the American Marketing Association and the Academy of Marketing Science.

Paul D. Berger

Boston University, School of Management, Marketing Department, 595 Commonwealth Avenue, Boston MA 02215, USA.

Tel: +1 617353 2655; e-mail: pdberger@bu.edu

Abstract Customer lifetime value (CLV) has been a mainstay concept in direct response/database marketing for many years. It has more recently become a major focus in 'mainstream' marketing. In spite, however, of all the mathematical models that have been developed to indicate formulas for calculating CLV, there is little, if any, detailed discussion in the literature of the actual applied calculations of CLV.

This paper reports on a real-world application of the use of CLV calculations to aid marketing strategy for a cruise-ship company. It covers the real-world issue of database cleaning and merging of the data into a 'usable' format, and developing customer migration models utilising these real data, as opposed to using mathematical models that 'approximate' repeat/retention patterns.

Customer migration analyses are performed and CLV determined for each of three years (eg the 'cohort of 1993,' those taking their first voyage with the cruise-ship company in 1993), for several different destinations and for different age segments. The implications and aftermaths of the analyses are discussed.

\section{INTRODUCTION}

Customer lifetime value (CLV) has been a mainstay concept in direct response/ database marketing for many years, as noted by Dwyer, ${ }^{1}$ and discussed by Keane and $\mathrm{Wang}^{2}$ in the publishing industry. It has since become a major focus in 'mainstream' marketing. In spite, however, of all the mathematical models that have been developed to indicate formulas for calculating CLV, there is little, if any detailed discussion in the 
literature of the actual applied calculations of CLV.

Berger and $\mathrm{Nasr}^{3}$ were the first to examine a series of models for the calculation of CLV. The primary objective of their paper was to consider different situations in terms of revenue streams, costs and probabilities, in order to develop various models that captured these different scenarios. Since then a number of papers have offered modifications to the formulas for calculating $\mathrm{CLV}^{4,5,6}$

Several research efforts have viewed the calculations of CLV as only a first step, and have focused on the use of CLV to optimise various marketing decision variables. For example, Blattberg and Deighton ${ }^{7}$ use CLV as the basis for determining, independently, the optimal amount of acquisition spending and retention spending. Berger and Nasr-Bechwati ${ }^{8}$ extend that work to a constrained allocation of promotional spending between acquisition and retention. Fan and Berger' ${ }^{9}$ have, in turn, extended this work to a dynamic, longitudinal time frame, rather than a one-time static decision situation. Berger and Bernstein ${ }^{10}$ apply the models in Berger and Nasr-Bechwati ${ }^{11}$ to a real-world application in the diagnostic selftesting industry. Reinartz and Kumar ${ }^{12}$ use CLV to investigate the actual profitability of long-term customers. Thomas $^{13}$ proposes further methodology for linking customer acquisition and customer retention.

The latest work in CLV goes a step beyond the previous work cited and considers CLV from a proactive, rather than reactive perspective. That is, instead of determining CLV and deciding on its strategic implications, the focus now is to determine how marketing variables impact on CLV. Some of the work then goes on to consider the optimisation of these decision variables. Notable among these is the book by Rust, Zeithaml and Lemon $^{14}$ and some of the work by Reinartz and Kumar ${ }^{15}$ on the relationship between customer lifetime and profitability. Further research efforts on connecting CLV to profitability by these aforementioned authors are currently under review.

Yet, all of these strategic analyses involving the use of CLV require the calculation of CLV. And, as noted earlier, while there are several mathematical models proposed, there is little literature that actually reports on the 'nitty-gritty' details of database manipulation and related activities, such as deciding on the time horizon, the merging and cleaning of data, and other 'hands-on' issues in CLV calculation. Naraj, Gupta and Narasimhan ${ }^{16}$ examine some of these aspects in a business-to-business (B2B) setting. The need for a detailed discussion of these issues is noted in Berger et al. ${ }^{17}$ in developing a comprehensive framework for customer asset management.

This paper reports on a real-world application of the use of CLV calculations to aid marketing strategy. The company involved is a cruise-ship company that will be called, for purposes of discussion, 'Joyful Voyages, Inc. (JV)'. The company sponsors year-round cruises to a variety of destinations, and advertises and promotes its cruises in accordance with industry norms and traditions. In order to maintain the confidentiality of the company's data, some of the destinations the company sails to have been slightly altered, and certain aspects of the data that might be too revealing have been transformed using a linear transformation. None of these changes materially affect any salient points of the discussion or results presented in subsequent sections of the paper. 


\section{CUSTOMER MIGRATION MODELS}

Jackson $^{18}$ groups buyers into two major categories - 'lost for good' and 'always a share.' The former category assumes that a customer is either totally committed to a vendor or totally lost to the vendor (and committed to some other vendor). The latter category assumes that a customer can experiment with another vendor, and may then return to the original vendor, with the latter occurrence having a different probability than that of a prospect who has never yet been a customer. Switching costs may play a large role in determining which behaviour is operative. Dwyer ${ }^{19}$ applied Jackson's taxonomy in direct response marketing and showed its applicability to CLV.

Here, a model consistent with 'always-a-share' is adopted. It clearly makes sense for the cruise-ship industry. Indeed, customers will often take a cruise during a given year, then skip a year (or two, or more), and then return to the focal company. Indeed, if the set of brand alternatives is broadened to include, not only other cruise-ship companies, but also other vacation packages (such as a flight to Venezuela, followed by a land tour), the always-a-share assumption is corroborated. Correspondingly, a customer migration model, which is characteristic of the always-a-share category is adopted. As will be seen, a customer migration model traces the customer from acquisition through the end of the time horizon, examining repeat rates as a function of recency of the previous purchase. When a large number of people are traced in this way, and if the patterns are shown to be reasonably consistent over time (ie consecutive years, in this case), confidence in the patterns is achieved.

It should be understood that it is not possible confidently to predict exactly which customers will fulfil a particular repeat pattern, but it is possible confidently to predict the number of customers who will fulfil the different repeat patterns. Of course, in general, it is not critical to know exactly which customers will be the ones to repeat or not repeat. It is, however, important to determine how many do what. Yet, this statement should be qualified in one way. If different marketing strategies that are based on identifying different market segments are being considered, then it may matter exactly who does what. Indeed, a segment-based set of strategies is addressed in a later section of the paper. Even then, however, the former statement holds if 'within segment' is added.

The customer migration model is applied (and the CLV determined) for several populations. The key

consideration was to examine the 'cohort of 19xx.' The focus was first on all of Joyful Voyages, Inc. customers who went on their first cruise with JV during 1993; the 'cohort of 1993'. It was decided that a five-year time horizon was appropriate; revenues and cost streams more than five years in the future would have a limited effect on CLV, and the effect would provide an understated (hence, conservative) CLV. In turn, this provides a cushion for various strategic decisions based on the CLV. The authors also focused on the cohort of 1994 and the cohort of 1995, in order to see if the customer migration model results were reasonably consistent from year to year. If so, the CLV results would be correspondingly consistent, assuming adjustments for inflation and any systematic price or cost changes.

In addition, the customer migration model and CLV were examined for different destinations. Going into the analysis, it seemed intuitive, and indeed very likely (in the opinion of JV's 
management), that the CLV should be different for a customer whose first trip was to Alaska, than for a customer whose first trip was to Bermuda. After all, a customer 'acquired' for a trip to Alaska has a larger profit for JV (mostly due to its price - more about this later) for this trip alone than a customer whose initial trip was to Bermuda. So, unless those customers whose first trip was to Bermuda repeat and/or 'buy up' to a much larger extent than those customers whose first trip was to Alaska, clearly the latter's CLV will exceed the former's CLV. Specifically, the authors considered four different JV destinations out of about 12 different destinations to which JV travels (most destinations are 'staples' and the same from year to year, at least in the 'intermediate run'; however, one or two of the less popular destinations may change from year to year). The four destinations will be called Alaska, Mexico, Bermuda and Central America, specific ports are omitted to maintain confidentiality.

When CLV is calculated for the various years and destinations, it should be noted that the acquisition cost is excluded. Whether CLV includes acquisition cost is a matter of choice. Indeed, it does not matter, as long as it is specifically indicated whether the CLV put forth does or does not include this cost.

\section{PREPARING THE DATA}

A key issue was the merging and cleaning of the data into a usable format. This is not unusual, but this mundane aspect of data manipulation is virtually never discussed in CLV analyses. It has been noted in other database surroundings such as list segmentation analysis in direct mail. ${ }^{20}$

At JV, customer data were entered into the database by a variety of employees, including account representatives, frontline customer service personnel, information systems personnel, etc. Some data were incomplete, and some data were clearly in error (eg a different location listed for two members of a family that clearly went on the same cruise). Indeed, in cross-referencing different numbers (eg a value for the total number of customers on a cruise and the value obtained by adding up the individual number of customers listed), it became clear that some data were missing. Of course, these discrepancies were not a total shock, given that database entry is often a lower priority than other, more customer-direct activities, such as direct-contact responses to customer inquiries and complaints.

Some of the discrepancies in numbers were caused by a few customers who were in a special price-discounted category, or in a non-paying category. These people were often in a separate part of the database, not organised in the same way as regular customers (eg not by customer identification number, but by geographic location). All inconsistencies in numbers required various merge and purge operations; without direct help from several company personnel, there was no way that all the files that needed to enter the merge/purge process would have been identified.

\section{The cohort of 1993}

Figure 1 presents the results for the cohort of 1993 (ie those customers who had their first cruise with JV during 1993) during the five-year time horizon, 1993 to 1997 . The way to interpret Figure 1 is as follows. There were 6,094 customers $(p=$ number of passengers $=6,094)$ who took their first cruise with JV during 1993. These 6,094 customers took a total of 6,198 cruises 


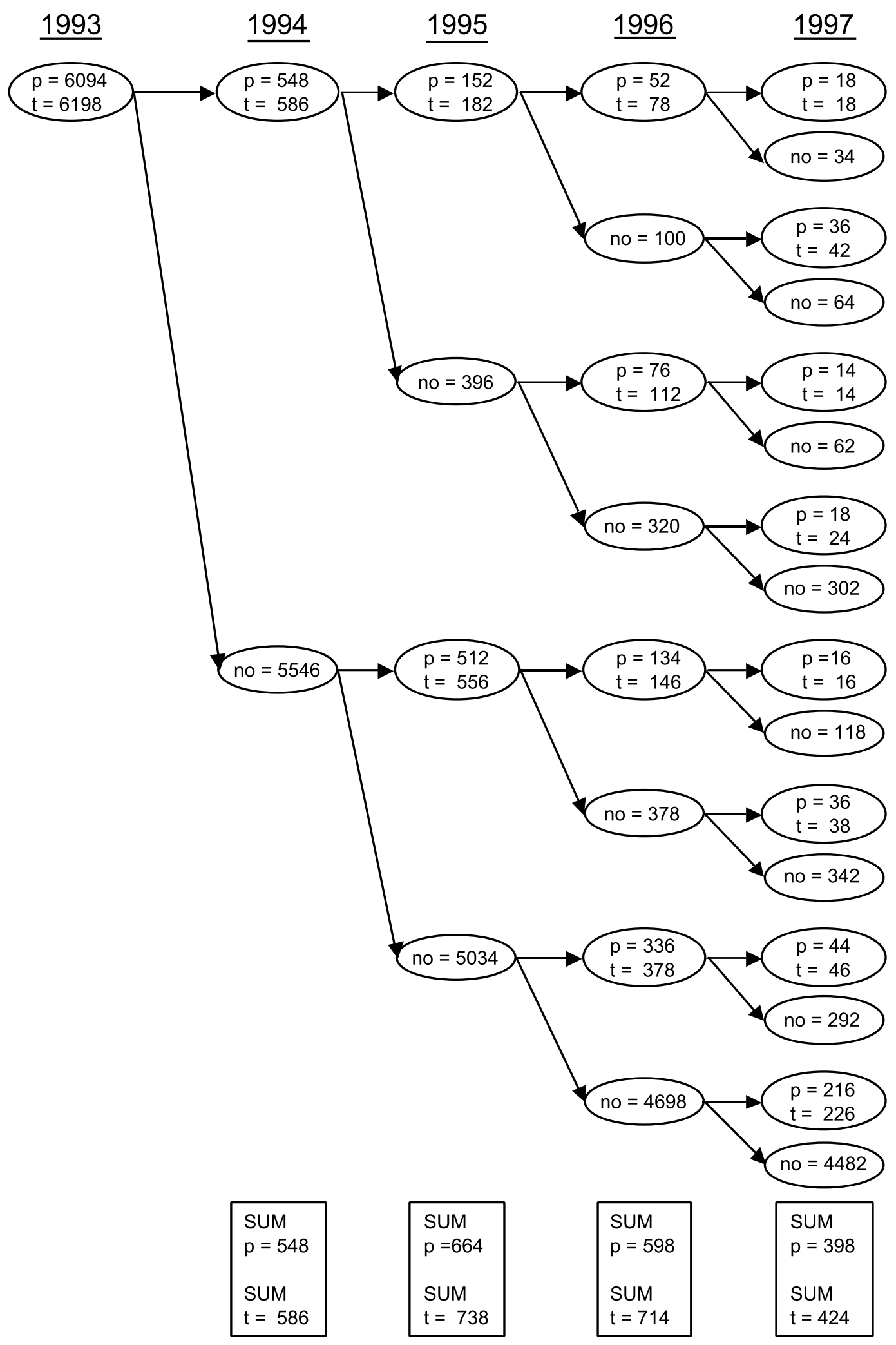

Figure 1: Cohort of 1993 
$(t=$ number of trips $=6,198)$ during 1993; that is, there were 104 repeat cruises during 1993 by these 6,094 firstyear customers. In actual fact, 102 of these customers took two cruises during 1993 and one customer took three cruises during 1993.

Out of these 6,094 customers, $p=548$ took at least one cruise during 1994, with a total of $t=586$ trips. Indeed, 5,546 of these 6,094 customers did not take a cruise with JV during 1994 ('no' = did not repeat with JV that year). Note, as should be expected, $548+5,546=6,094$. Out of the 548 who took a cruise during 1994, 152 took at least one cruise during 1995; perhaps more interestingly, out of the 5,546 customers who did not take a cruise during 1994, 512 took at least one cruise during 1995; and so forth. The figure traces all customers through the five-year period. Summing the ' $p=$ ' and 'no $=$ ' values in the 1997 (last) column, 6,094 is obtained, confirming that the migration of the entire cohort of 1993 customers has been accounted for.

The values in the box at the bottom of each year are the total number of passengers ( $~ p=$ '), and the total number of cruises they took (' $t=$ '). Thus, 548 of the 6,094 cohort of 1993 customers took at least one cruise during 1994, the total number of cruises being 586; similarly for the $p=664$ and $t=738$ for 1995, and so forth.

An interesting question that is not directly tabulated on the figure is 'How many of the original 6,094 customers of the cohort of 1993 actually took at least one (repeat) cruise during the 1994-1997 period?'. It is, of course, not the sum of 548 , 664, 598 and 398 values, since that total includes 'repeat repeaters'. The answer is 1,612. This value is found by taking the sum of 548 in 1994 , 512 in 1995, 336 in 1996 and 216 in
1997, and $(548+512+336+$ $216)=1,612$. When the CLV per cohort-of-1993 customer is computed, this value of 1,612 will not, in itself, be directly relevant, since it is the total number of additional cruises taken that matters (along, of course, with appropriate net present value, revenue and promotional and other cost considerations).

A corresponding diagram was developed for each of the four destinations mentioned earlier. Figure 2 shows one of them, that for the cohort of 1993 destination - Mexico. The total number of repeat cruises taken by the 1,278 customers of the Mexico cohort of 1993 is $478(=122+160+112+84)$, yielding a percentage of repeat trips of $100 \times(478 / 1,278)=37.4$ per cent. For the cohort of 1993 as a whole, it is $100 \times(2,462 / 6,094)=40.4$ per cent. While the actual results depend on the timing of the extra trips, as well as several other factors to be addressed in the next section, if everything else were equal, this lower repeat probability could suggest that an acquired customer from the Mexico cohort of 1993 might not be as valuable as the average acquired customer for the overall cohort of 1993. Actual CLVs will be provided for all four of the destinations alluded to earlier.

Customer migration diagrams were also developed for the cohort of 1994 and the cohort of 1995. The diagrams look similar to the cohort of 1993 diagram. While, however, the cohort of 1993 numbered 6,094, the cohort of 1994 numbered 7,166, and the cohort of 1995 numbered 7,758.

\section{DETERMINATION}

This section describes how the CLV was determined/calculated for the various cohorts. There are several mathematical formulas available for the CLV 


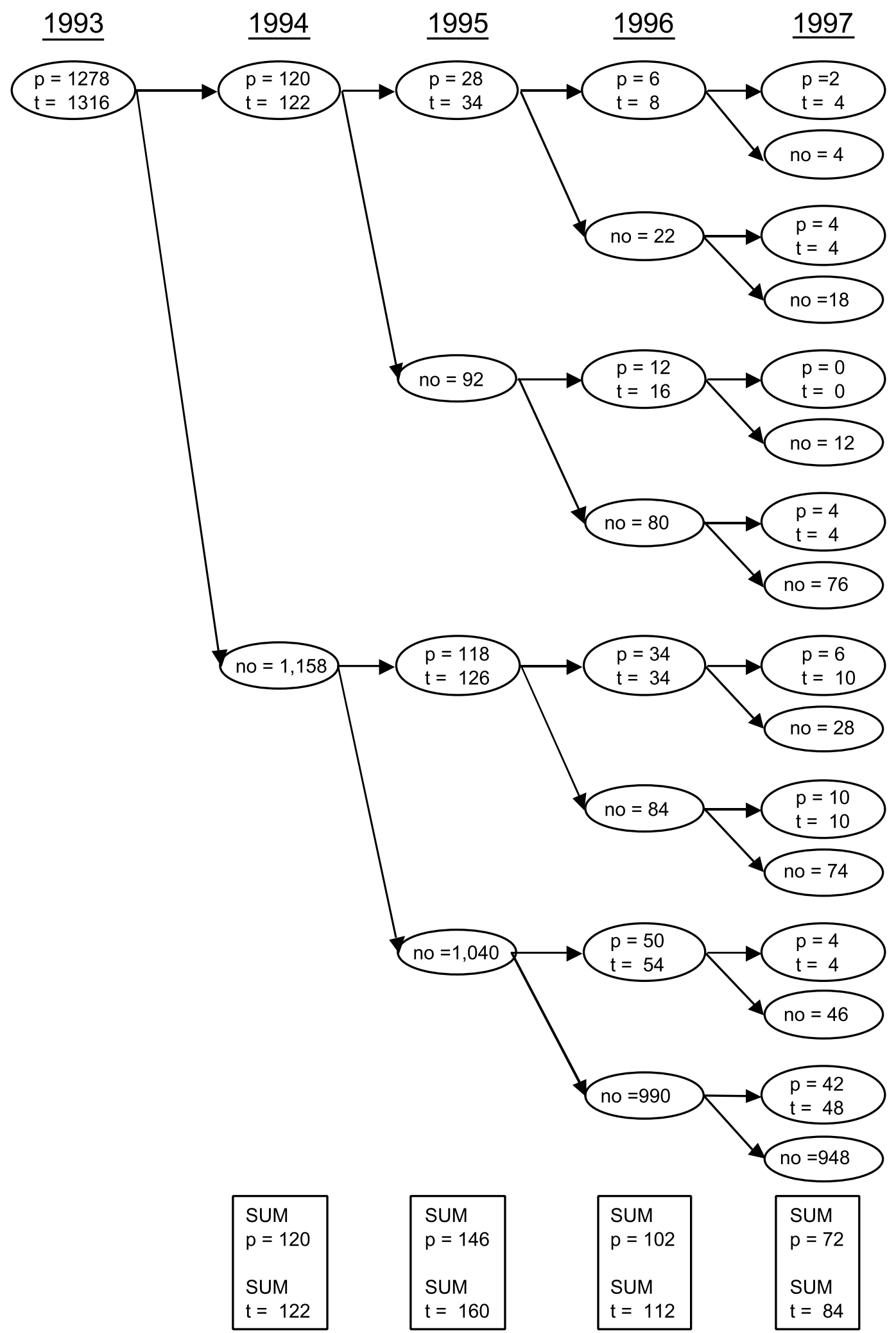

Figure 2: Cohort of 1993 - Mexico 
calculations; ${ }^{21}$ however, some simplifying assumptions were made that, after investigation, the authors were convinced had no material impact on the final CLV values. For example, it was assumed that all revenues and costs for the cruises, as well as promotional costs, took place in the middle of the year. In actuality, revenue comes in during the entire year as cruises take place throughout the year.

In essence, CLV can be described as the present value of 'all future gross contribution margins, minus all promotional costs (or, one could say, "retention costs"). ${ }^{22}$ Of course, for a given individual customer, these values are not known with certainty. They depend, among other things, on how long the customer is retained (if at all) and the degree to which he/she upgrades in terms of the size of future purchases. When, however, averages are taken over a large number of customers, CLV can be obtained, which, to be technical, is an expectation or expected value. This is no different, for example, from when a mailing list in a catalogue mailing is segmented. It is not known exactly which customers will buy this time, but it may be possible to say with great confidence that the proportion (ie response rate) will be within very precise (ie narrow) limits - because the estimate is based on a large sample size. Thus, CLV should, perhaps, be labelled ECLV - the expected value of a customer's lifetime value. (While it is likely that marketers working in this area would all agree with this statement, many factors mitigate against a notational change ever taking place.)

The CLV determination for the cohort of 1993 is now computed. A discount rate for marketing investments of 15 per cent is assumed. First, the present value of future gross margins is examined. Discussion with JV management revealed that they view gross margin as 85 per cent of the price of a cruise. Indeed, once the cruise ship is sailing anyway, there is little marginal cost to an additional passenger or two filling a room that would otherwise be empty, because JV, as most cruise lines, schedule ships very far in advance. The main costs do not involve food or lodging at all. There are 'tons of food' left over after every meal, and the stewards who clean rooms, etc are paid by voyage, not by room (although they receive more tip money if they service more rooms). A small component of the incremental cost is administrative (printing tickets, etc); the main incremental costs are land costs - for example, the admission cost for an excursion to a museum that is part of the voyage's itinerary.

The average cruise price for the cohort of 1993's initial voyage was US $\$ 3,899$. It was determined that the price of cruises from the repeats of the cohort of 1993 averaged 12 per cent higher per year. Some of this was, of course, due to inflation and increased voyage prices in general. On the other hand, some of this price increase was due to upgrading, as there is a lot of evidence showing that customers tend to spend more and be more profitable as they spend more time with the same company. ${ }^{23}$ This led to the following calculation of expected profit/person for the cohort of 1993 (using $\pi$ for profit). Taking present value back to mid-1993, the time of the assumed initial revenues and costs (excluding acquisition costs, as noted earlier), a total of $\$ 28,201,236$ is obtained (see Table 1).

Dividing total PV of revenues by the number of passengers for the cohort of 1993, 6,094, gives:

$$
28,201,236 / 6,094=\$ 4,628
$$

Note that revenue and profit is 
Table 1

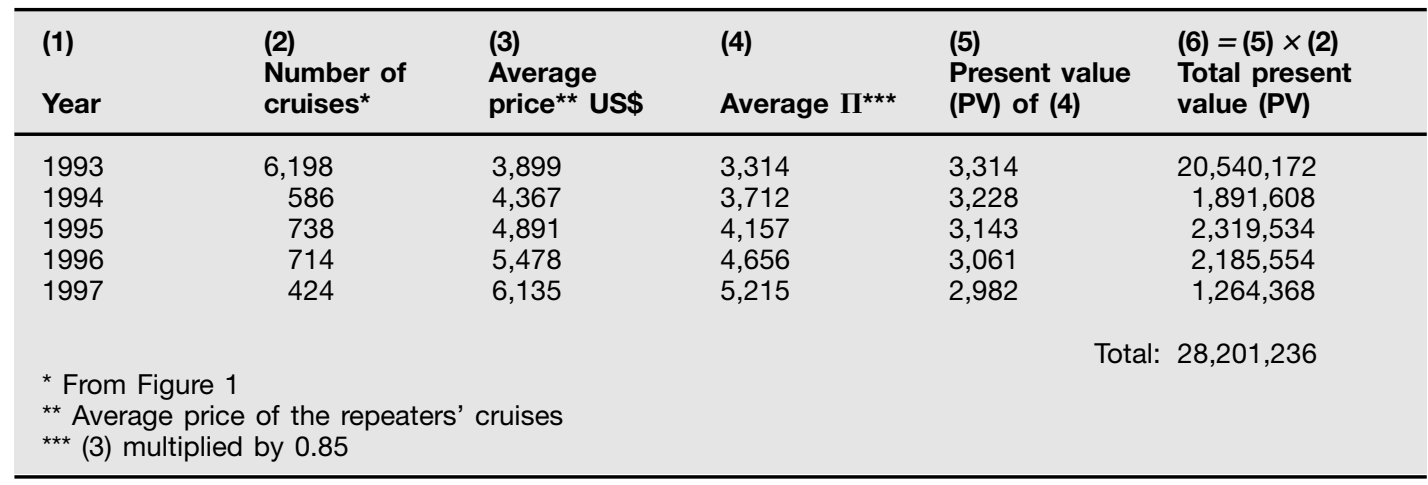

Table 2

\begin{tabular}{lll}
\hline Year & Cost US\$ & Present value (PV) of cost US\$ \\
\hline 1993 & 12 & 12 \\
1994 & 24 & 20.87 \\
1995 & 24 & 18.15 \\
1996 & 24 & 15.78 \\
1997 & 24 & 13.72 \\
& & Total $\$ 80.52$ \\
\hline
\end{tabular}

computed from the number of cruises taken, but divided by the number of distinct passengers.

The promotional costs are considered now. JV noted that they promote to customers (ie those who have sailed with them before) by sending out extensive mailings - 30 mailing pieces per year. The mailing cost for the time period studied here averaged $\$ 0.80 /$ mailing. Thus, each household received $30 \times(0.8)=$ US $\$ 24$ worth of mailings per year. They also had information from the past that, on average, there were 1.7 passengers per household. Thus, 6,094 passengers corresponded with $6,094 / 1.7=3,585$ households. In calculating the present value of these promotion costs, it was assumed that $\$ 12$ per household was spent in 1993, and $\$ 24$ per household in subsequent years. (A customer in the cohort of 1993 was, on average, a customer for half of 1993, while being a customer for all the years
1994 to 1997.) Thus, present value per household was determined as shown in Table 2.

Cost per passenger was US $\$ 80.52 / 1.7=$ US $\$ 47.36$ (or, alternatively, if US $\$ 80.52$ is multiplied by 3,585 , and then divided by 6,094 , the same value is achieved). CLV is now computed to be

$$
\$ 4,628-\$ 47=\$ 4,581
$$

and the ratio of CLV to profit-offirst-voyage to be:

$$
\begin{gathered}
\mathrm{CLV} /(\text { First voyage profit) } \\
\quad=4,581 / 3,314=1.38 .
\end{gathered}
$$

This ratio, as will be seen, is remarkably consistent from year to year, while not consistent from destination to destination. The repeat rate, in terms of number of passengers, is 26.5 per cent (=1,612/6,094); that is, through 1997 , 
Table 3

\begin{tabular}{lllll}
\hline Destination & $\begin{array}{l}\text { Passengers } \\
\text { repeating \% }\end{array}$ & CLV \$ & $\begin{array}{l}\text { I, first } \\
\text { cruise } \$\end{array}$ & CLV/II \\
\hline Overall & 26.5 & 4,581 & 3,314 & 1.38 \\
Alaska & 19.8 & 4,089 & 3,166 & 1.29 \\
Mexico* & 25.8 & 3,559 & 2,617 & 1.36 \\
Bermuda & 27.6 & 3,040 & 2,054 & 1.48 \\
Central America & 36.3 & 6,694 & 3,999 & 1.67 \\
\hline
\end{tabular}

* Values in the first three columns can be derived from Figure 2

26.5 per cent of the 6,094 cohort of 1993 took at least one more voyage.

An additional comment on the five-year time horizon - further investigation revealed that, for the cohort of 1993, only about 100 (actually, 102) cruises, and fewer than 100 passengers out of the original 6,094 repeated after 1997. Similar behaviour was observed about the cohort of 1994. Thus, it became clear that, while the five-year time horizon did lead to a conservative, undersized CLV, the difference was relatively minor.

\section{Aftermath: The epiphany}

The CLV of US $\$ 4,581$ was a major revelation that dramatically affected JV's acquisition strategy. Prior to this analysis, JV management would never spend more than $\$ 3,314$ to acquire a passenger. For example, if historical data told them that a set of advertisements in the New York Times that cost $\$ 20,000$ would, on average, generate five, or even six new customers, management would not undertake the advertising, since five customers generated would result in an acquisition cost per customer of US $\$ 4,000$, and even six customers generated would result in an acquisition cost per customer of US\$3,333. Now, aware of CLV (both the concept and the actual numerical results), an advertisement that 'did this well' was welcomed - especially since the CLV numbers are conservative (again, as noted, the CLV does not include any residual business after five years).

\section{Separate destinations}

Separate calculations were performed for each of the aforementioned destinations. The results for 1993 are shown in Table 3.

As can be seen, CLV, repeat percentages, and ratios of CLV to profit values vary for the different destinations. Relatively speaking, the Central American voyage is far more profitable than the other three destinations; however, in this case, it is not so much the price of the initial voyage, but the repeat probabilities that are driving this profitability. There is something about this destination, or the customers who choose this destination for their maiden voyage with $\mathrm{JV}$, that should be investigated, and, if determined to be transferable in some way, should be 'bottled'. Indeed, while the CLV rank order is the same as the price and profit rank order, the ratios (last column) are quite different, and may represent very different acquisition strategies.

\section{The cohort of 1994 and 1995}

Analyses were also performed for the cohort of 1994 and 1995, each with the same five-year time horizon. Results, shown in Table 4, are provided only for the overall cohort.

Note the remarkable consistency of 
Table 4

\begin{tabular}{lllll}
\hline Year & $\begin{array}{l}\text { Passengers } \\
\text { repeating }\end{array}$ & CLV \$ & $\begin{array}{l}\text { I, first } \\
\text { cruise } \$\end{array}$ & CLV/II \\
\hline 1993 & 26.5 & 4,581 & 3,314 & 1.38 \\
1994 & 24.7 & 4,862 & 3,573 & 1.36 \\
1995 & 26.1 & 5,162 & 3,780 & 1.37 \\
\hline
\end{tabular}

Table 5

\begin{tabular}{llll}
\hline 1993 & $<60$ years & $\geq 60$ years & Overall \\
\hline Repeat probability & $18.8 \%$ & $30.0 \%$ & $26.5 \%$ \\
CLV & $\$ 4,207$ & $\$ 4,753$ & $\$ 4,581$ \\
\hline
\end{tabular}

the repeat ratio and the ratio of CLV to profit of first voyage. Even the CLVs are consistent if considered in a certain light. The CLV went up by 6.1 per cent from 1993 to 1994. Much of that, however, simply reflected across the board increases in ticket prices. From 1994 to 1995, the increase was 6.2 per cent, very close to the previous year's increase.

This consistency engendered significant confidence in the CLVs on the part of JV's management. This issue had been one of great concern entering the analyses - whether there would be consistency and, thus, a 'comfort zone' for extrapolating results. Of course, each year, another five-year period comes to a close and an analysis can be performed year-by-year to determine if any fundamental changes have occurred to change the interrelationships that had previously endured. (And, of course, like any good consultant, how to perform the analyses was transmitted to JV employees, so that they were able to continue analyses without the necessity for the consultants' presence in the future.)

\section{FURTHER SEGMENTATION: AGE}

JV management was very anxious to inquire about the role of age in determining CLV. Management split into two groups on the issue of whether general marketing activities should begin to target 'younger' people (under 60). For the cohort of 1993, 31 per cent were under 60 and 69 per cent over 60 . For the cohort of 1994, it was very similar, 32 per cent under 60 and 68 per cent over 60 . One side of the argument was: 'Clearly, folks over 60 like our cruises, and we should beef up our efforts through (perhaps, more narrow) targeting to reach more of these people'. The argument on the other side was: 'Folks younger than 60 have, relatively speaking, substantially more years left for potential repeat business before they die or are too old for a cruise, and for us, the under 60 market is a less saturated market. Therefore, there is more potential incremental gain and we should explicitly target them'.

In order to resolve this dichotomy of opinion, the CLV was determined for the cohort of 1993 and cohort of 1994 for each age segment (Table 5). As can be seen, the CLV is much greater for the $\geq 60$ segment. Since, however, one of the arguments in favour of the pro $<60$ segment was the additional time that the younger segment had, the next step was to extrapolate the repeat trips for the next ten years, using two more years of actual data (1998 and 1999), and eight 
Table 6

\begin{tabular}{llll}
\hline $\mathbf{1 9 9 4}$ & $<60$ years & $\geq 60$ years & Overall \\
\hline Repeat probability & $16.8 \%$ & $28.4 \%$ & $24.7 \%$ \\
CLV & $\$ 4,125$ & $\$ 5,209$ & $\$ 4,862$ \\
\hline
\end{tabular}

years of projections, based on curve fitting. The results for the next ten years added US $\$ 220$ to the CLV for the $<60$ segment, while adding US\$101 to the $\geq 60$ segment. Thus, even when the extra time was taken into account, the $>60$ segment was still a clear winner.

For 1994, the results were similar, although there was an even larger disparity between the $<60$ segment and $\geq 60$ segment (Table 6). For 1994, the ten-year extrapolation resulted in adding US $\$ 213$ for the $<60$ segment and US $\$ 97$ to the $\geq 60$ segment.

The debate about $<60$ vs $\geq 60$ ended quickly, although debate continued whether to do 'the same as we have been doing in terms of targeting', or to target the $\geq 60$ years more narrowly. After all, JV believed (correctly so) that the $<60$ segment did have a nice CLV for JV, even though it was not as high as that for the $\geq 60$ segment, and there was some question whether a more targeted campaign might result in fewer customers overall.

\section{SUMMARY AND CONCLUSIONS}

In this paper, the authors illustrated the actual determination of CLV for various groups of people, and the determination of the CLV for different age segments within these groups. JV significantly altered its marketing strategy due to the CLV and related analyses. This was especially true on the acquisition side of its business, as well as related issues of segmentation by age. It should be said that age was studied not only because it was a potentially important segmentation variable, but also because it was available in the database. There were other variables suggested as potential segmentation variables but, they were not available on the database (eg income).

JV did not overtly change anything on the retention side of its business. There is great potential for changes in retention strategy to result in additional profits, as illustrated by several of the earlier mentioned references that dealt with the trade-off between acquisition and retention spending. Indeed, this is especially true given the richness of JV's actual data, now that the data are in a very usable form.

The analyses, by considering specific migration models based on real data, and not just a 'mathematical model', with its inherent compromises, enabled the authors to measure truly the repeatability/retention aspect of the populations being evaluated. It is very unlikely that any theoretical/ mathematical model would have easily captured many salient features of the data - for example, the non-monotonicity of the repeat pattern (ie consistently, there were more repeats in the second year after a customer's first voyage than in the first year after his/her first voyage).

This paper also discussed many other aspects of CLV determination and use that is glossed over, if mentioned at all, by most research addressing CLV issues - for example how profits are thought about and obtained, the nitty-gritty issues of passengers vs households, determining the true promotional costs and how they are calculated, etc. 
The authors believe that the ingredients of this paper are necessary and useful precursors to the sophisticated analyses enabled by the ideas codified in the CLV paradigm.

\section{References}

1 Dwyer, R. (1989) 'Customer lifetime valuation to support marketing decision making', Journal of Direct Marketing, Vol. 3, No. 4, pp. 8-15.

2 Keane, T. and Wang, P. (1995) 'Applications for the lifetime value model in modern newspaper publishing', Journal of Direct Marketing, Vol. 9, No. 2, pp. 59-66.

3 Berger, P. D. and Nasr, N. I. (1998) 'Customer lifetime value: Marketing models and applications', Journal of Interactive Marketing, Vol. 12, No. 1, pp. 17-30.

4 Mulhern, F. J. (1999) 'Customer profitability analysis: Measurement, concentration, research directions', Journal of Interactive Marketing, Vol. 13, No. 1, pp. 25-40.

5 Reinartz, W. J. and Kumar, V. (2000) 'On the profitability of long-life customers in a noncontractual setting: An empirical investigation and implications for marketing', Journal of Marketing, Vol. 64, No. 4, pp. 17-35.

6 Rust, R. T., Zeithaml, V. A. and Lemon, K. N. (2000) 'Driving customer equity: How customer lifetime value is reshaping corporate strategy', Free Press, New York.

7 Blattberg, R. C. and Deighton, J. (1996) 'Managing marketing by the customer equity test', Harvard Business Review, Vol. 74, July-August, pp. 136-144.

8 Berger. P. D. and Nasr-Bechwati, N. I. (2001) 'The allocation of promotion budget to maximize customer equity', OMEGA, Vol. 29, pp. 49-61.

9 Fan, S. and Berger, P. D. (2001) 'The optimal allocation between acquisition and retention spending over multiple time periods', International Quarterly Journal of Marketing, Vol. 1, No. 4, pp. 199-210.

10 Berger, P. D. and Bernstein, D. (2002) 'The optimal trade-off between acquisition and retention promotion - An application to the diagnostic self-testing market', International Quarterly Journal of Marketing, Vol. 2, No. 4, pp. 47-54.

11 Berger and Nasr-Bechwati (2001) op. cit.

12 Reinartz and Kumar (2000) op cit.

13 Thomas, J. S. (2001) 'A methodology for linking customer acquisition to customer retention', Journal of Marketing Research, Vol. 38, May, pp. 262-268.

14 Rust et al. (2000) op cit.

15 Reinartz and Kumar (2000) op. cit.

16 Naraj, R., Gupta, M. and Narasimhan, C. (2001) 'Customer profitability in a supply chain', Journal of Marketing, Vol. 65, July, pp. 1-16.

17 Berger, P. D., Bolton, R. N., Bowman, D., Briggs, E., Kumar, V., Parasuraman, A. and Creed, T. (2002) 'Marketing actions and the value of customer assets: A framework for customer asset management', Journal of Service Research, Vol. 5, No. 1, pp. 39-54.

18 Jackson, B. (1985) 'Winning and keeping industrial customers', Lexington Books, Lexington, MA.

19 Dwyer (1989) op. cit.

20 Berger, P. D. and Magliozzi, T. L. (1992) 'The effect of sample size and proportion of buyers in the sample on the performance of list segmentation equations generated by regression analysis', Journal of Direct Marketing, Vol. 6, No. 1, pp. 13-22.

21 Berger and Nasr (1998) op. cit.

22 Roberts, M. and Berger, P. D. (1999) 'Direct marketing management', 2nd ed., Prentice-Hall, Upper Saddle River, New Jersey.

23 Kalwani, M. U. and Narayandas, N. (1995) 'Long-term manufacturer- supplier relationships: Do they pay off for the supplier firm?', Journal of Marketing, Vol. 59, No. 1, pp. 1-16. 